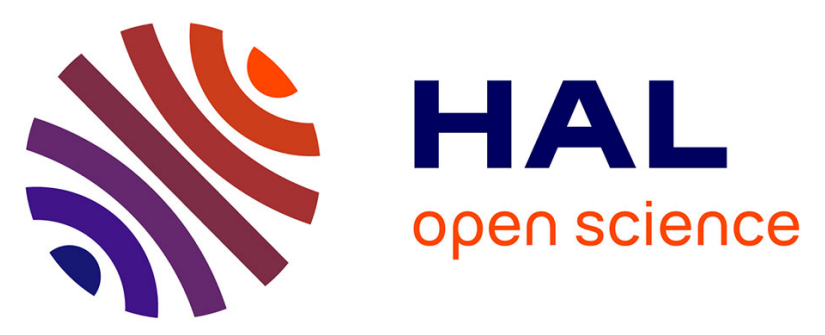

\title{
Evolution of thermo-physical properties and annealing of fast neutron irradiated boron carbide
}

\author{
D. Gosset, B. Kryger, J.-P. Bonal, C. Verdeau, K. Froment
}

\section{To cite this version:}

D. Gosset, B. Kryger, J.-P. Bonal, C. Verdeau, K. Froment. Evolution of thermo-physical properties and annealing of fast neutron irradiated boron carbide. The Nuclear Materials Conference, 2016 NUMAT 2016, Nov 2016, Montpellier, France. cea-02435072

\section{HAL Id: cea-02435072 \\ https://hal-cea.archives-ouvertes.fr/cea-02435072}

Submitted on 10 Jan 2020

HAL is a multi-disciplinary open access archive for the deposit and dissemination of scientific research documents, whether they are published or not. The documents may come from teaching and research institutions in France or abroad, or from public or private research centers.
L'archive ouverte pluridisciplinaire HAL, est destinée au dépôt et à la diffusion de documents scientifiques de niveau recherche, publiés ou non, émanant des établissements d'enseignement et de recherche français ou étrangers, des laboratoires publics ou privés. 


\title{
Evolution of thermo-physical properties and annealing of fast neutron irradiated boron carbide
}

\author{
Dominique Gosset (CEA Paris-Saclay, DEN/DANS/DMN/SRMA/LA2M) \\ Bernard Kryger (retired) \\ Jean-Pierre Bonal (CEA-Paris-Saclay, DEN/DDCC/UADF/CCOD) \\ Caroline Verdeau (CEA Cadarache, DEN/CAD/DTN) \\ Karine Froment (CEA Grenoble, DRT/LITEN/ARC NUC)
}

\begin{abstract}
Boron carbide is widely used as a neutron absorber in most nuclear reactors, in particular in fast neutron ones. The irradiation leads to a large helium production (up to $10^{22} / \mathrm{cm}^{3}$ ) together with a strong decrease of the thermal conductivity. In this paper, we have performed thermal diffusivity measurements and X-ray diffraction analyses on boron carbide samples coming from control rods of the French Phenix LMFBR reactor. The burnups range from $10^{21}$ to $8.10^{21} / \mathrm{cm}^{3}$. We first confirm the strong decrease of the thermal conductivity at the low burnup, together with high microstructural modifications: swelling, large microstrains, high defects density, and disordered-like material conductivity. We observe the microstructural parameters are highly anisotropic, with high micro-strains and flattened coherent diffracting domains along the (00l) direction of the hexagonal structure. Performing heat treatments up to high temperature $\left(2200^{\circ} \mathrm{C}\right)$ allows us to observe the material thermal conductivity and microstructure restoration. It then appears the thermal conductivity healing is correlated to the micro-strain relaxation. We then assume the defects responsible for most of the damage are the helium bubbles and the associated stress fields.
\end{abstract}

Keywords. Boron carbide, neutron absorber, thermal conductivity, microstructure, heat treatments. 


\section{Introduction}

Boron carbide is widely used as a neutron absorber for the control, safety and protection of nuclear reactors.

This is due to the conjunction of a high temperature melting and abundance and $a{ }^{10} \mathrm{~B}$ high neutron absorption cross section in the whole neutron energy spectrum. The main limitations arise from brittleness and the production of large quantities of helium and heat during the $(n, \alpha)$ neutron absorption reactions. As a matter, the $(n, \alpha)$ reaction is exothermal (about $2.6 \mathrm{MeV}$ per capture). In a control rod, the burnup (neutron capture density) can be as high as $10^{22} / \mathrm{cm}^{3}$ per year, this leading to a volume power about $150 \mathrm{~W} / \mathrm{cm}^{3}$. This generates high thermal gradients in the absorber material pellets leading to an extensive pellet cracking (Figure 1).

It is then of primary importance to have a good knowledge of the thermal conductivity of the material and its evolution during irradiation. It is now well known that the thermal conductivity degrades under neutron irradiation $[1,2,3,4,5]$. We present here results we have obtained from materials irradiated in the French LMFBR Phenix reactor. Some of those results, already published in $[6,7,8,9]$ are here re-examined. This aims first at proposing complementary results on materials somewhat different from those in other studies.

Moreover, the thermal conductivity loss certainly arises from helium accumulation but also from structural damage. In order to estimate this contribution, we have performed X-ray diffraction analyses of the materials. The crystal structure of boron carbide is well known $[10,11]$. It is built by a close packing of nearly regular icosahedra (composition close to $\mathrm{B}_{11} \mathrm{C}$ ) located on the apex of a rhombohedral network. The main diagonal of the rhombohedra is occupied by a linear chain (most frequent composition $C B C$ ), this leading to the $\mathrm{B}_{11} \mathrm{C}-\mathrm{CBC}$ cell composition, i.e. $\mathrm{B}_{4} \mathrm{C}$. The rhombohedral structure is most often described in a hexagonal frame. Most of observations have shown that during neutron irradiations, helium accumulate as flat bubbles perpendicular to the (00.I) direction, generating strong and anisotropic internal stresses.

At last, thermal treatments have been performed up to high temperature in order to determine the temperature ranges in which the thermal conductivity and the structure heal.

\section{Experiment}

The irradiations have been performed in the French Phenix Sodium cooled Fast Reactor in the frame of the development of the absorber rods of the Superphenix reactor. Two experiments are here considered: 
- The first one (Hyperbare-1) aimed at testing advanced control rods designs. In this case, the boron carbide pellets are inserted in a metallic sheath aiming at reducing the fragments relocation and the shroud carburization [12].

- The second one (Fracasse) aimed at analyzing the cracking of the material at the beginning of life as a function of the material manufacturing process and the pellets geometry and density.

Their main characteristics are reported on Table 1.

The boron carbide has been elaborated with the magnesothermal process [10], the French reference process of the time. After acid washing, this leads to a micronic powder. As compared to the carbothermal elaboration process, the magnesothermal process then leads directly to a material with a small, homogeneous grain size without crunching and sieving steps. Other differences stand in the specific surface of the powder, the impurity composition and content (Mg vs Fe, oxygen, free carbon), this leading to somewhat different hot pressing conditions (somewhat lower for the magnesothermal process).The powder is then hot-pressed in a graphite die to obtain cylindrical pellets, the hot-pressing conditions (about $2000^{\circ} \mathrm{C}$, $50 \mathrm{MPa}, 1$ hour) are adjusted to obtain a high density (circa $96 \%$ ) and keep as a small grain size as possible. The pellets are then machined to remove the reaction surface and to obtain the required dimensions.

The boron carbide pellets are stacked in stainless steel shrouds. The lower and upper plugs are porous to allow sodium circulation inside the rod, between the $\mathrm{B}_{4} \mathrm{C}$ pellets stacking and the clad. This allows first cooling the absorber and second evacuating the released helium arising from the $(n, \alpha)$ absorption reactions. This then allows rather large $\mathrm{B}_{4} \mathrm{C}$ pellets diameter, since the surface temperature remains low, and short control rods, since no expansion chambers for released helium are required. The main drawback is an accelerated chemical interaction with the cladding (boronation and/or carburization).

After irradiation, the control rod is sodium drained, then submitted to non-destructive examinations (metrology, neutron and X-ray scanning). The rod is then cut to perform the destructive examinations: burnup, metallography, density, and so on. Before the analyses, selected sections are heated to $500^{\circ} \mathrm{C}$ under a vacuum in order to remove residual sodium.

In the case of the Hyperbare- 1 experiment, 2 control elements have been analyzed. The burnup and boron carbide swelling distribution along the rod height are reported in Figure 2. The exponential-like variation of the burnup results from the neutron distribution in the reactor (flux and energy spectrum) and the moving of the control rod in the core during its life. The similar distribution of the swelling confirms a quasi-linear variation as a function of burnup at least up to $10^{22} / \mathrm{cm}^{3}$, about 0.15 vol. $\%$ per $10^{20} \mathrm{capt} . / \mathrm{cm}^{3}[2,4,12]$.

In the case of the Fracasse experiment, short $(40 \mathrm{~cm})$ elements have been irradiated in fixed position, located at the mid-plane of the Phenix core, this leading to a nearly flat neutron flux then boron burnup distribution. 


\section{Analyses}

\section{Thermal conductivity}

The thermal conductivity is obtained from the classical indirect method:

$k=d D C p$

Where $\mathrm{d}$ is the density of the material, $\mathrm{D}$ the thermal diffusivity and $\mathrm{Cp}$ the heat capacity.

The density has been determined by weighting and mercury pycnometry of fragments before they are cut for the thermal diffusivity measurements. An estimation of swelling is then determined from the difference between the initial and the post-irradiation densities. This then does not take into account helium or lithium partial release, this leading to an overestimation of swelling.

The heat capacity has not been determined. It is assumed to be equal to the non-irradiated material one.

The thermal diffusivity has been determined using the Flash method. This requires flat samples with parallel faces. For this, we have selected fragments from the irradiated pellets. The fragments are then sliced with a diamond-wire saw in order to obtain platelets with a thickness about $2 \mathrm{~mm}$ and a size as large as possible. For the Fracasse experiment, the small diameter pellets are not cracked, and then discs are rather easily obtained. For the Hyperbare experiment, at low burnups, irregular polygons about $1 \mathrm{~cm}$ large have been obtained. For the highest burnups, the fragments are smaller and most often cracked: the samples were about 6 to $8 \mathrm{~mm}$ large.

The Flash method consists in illuminating one face of the sample (here with a YAG-laser) and recording then analyzing the thermal transient (thermogram) on the other face. The samples are arranged on an alumina sample holder. The thermograms are recorded with a K-thermocouple slightly pressed on the center of the rear sample surface. The analysis of the thermograms uses a two-dimensional resolution of the heat equation [13] then assumes the sample is a thin disc. Due to the irregular shape of the sliced fragments, an uncertainty is introduced, the value is not really known: simulations show the thermal diffusivity values obtained with the model differ by about 1 percent between a disc and a square of the same surface. This has also been checked analyzing square or disc samples of standard materials.

The measurements are performed in a furnace under helium. The possible temperature range is from room temperature (RT) to $1000^{\circ} \mathrm{C}$. But for the samples irradiated at low temperature, the measurements are first restricted from RT to the estimated irradiation temperature, in order to avoid annealing of the material, and then the range is progressively increased as the successive heat treatments are made. 


\section{X-ray diffraction}

The X-ray analyses have been performed with a INEL-CPS120 diffractometer (presently Thermo Fisher Scientific) on the same samples used for the thermal diffusivity analyses. The detector is a multichannel analyzer, with about 4000 channels $0.03^{\circ}$ wide on $120^{\circ}(2 \theta)$. This allows fast recording of the diagrams. The incident beam ( $\mathrm{Cu}$ k $\alpha 1$ line, Ge (111) monochromator) is parallel (size $100 \mu \mathrm{m} \times 5 \mathrm{~mm}$ ) and reaches the sample under a fixed incidence $\left(10^{\circ}\right)$.

Due to the low-Z elements constituting boron carbide, the absorption coefficient is very low $\left(\mu \sim 6 \mathrm{~cm}^{-1}\right)$. This leads to very long penetration depths $(1 / \mu \sim 150 \mu \mathrm{m})$, this generating very asymmetric diffraction lines and a strong apparent decentering. Those distortions have to be corrected in order to determine the actual position and intrinsic width of the lines. In previous papers [6, 7], we used an explicit formulation of the line profile taking into account this absorption effect, this requiring a quite tedious line-to-line analysis on a set of non-overlapping lines on the diagrams. Here, we have used a Rietveld program (XND) which has been modified to take into account the asymmetric configuration of the facility [14, 15]. In that case, the asymmetry is simulated by special functions in the experimental description of the experiment [16] the parameters values of which are determined on a non-irradiated sample. In the XND program, the line profiles are Voigt functions. The material component to the lines profile is supposed to have two contributions, one depending on $1 / \cos (\theta)$, the second one on $\tan (\theta)$. These are the two well-known contributions arising first from a size effect (dimension of the coherent diffracting domains, Scherrer approximation) and second from microdistortions. This then intrinsically corresponds to the classical Williamson-Hall approach [17]. Anisotropic linewidths can be introduced depending on the crystallographic directions.

\section{Heat treatments}

We have first analyzed samples with different burnups. For the low burnups, for which large samples are available, we have then performed heat treatments in order to analyze the restoration of the damage on the thermal conductivity and the structure. Thus, 30 minutes heat treatments were performed under vacuum in a graphite furnace from the estimated irradiation temperature up to $2200^{\circ} \mathrm{C}$ by $100{ }^{\circ} \mathrm{C}$ steps. A Pyrox (presently AET-technologies) V180-25 furnace was used, allowing fast heating $\left(30^{\circ} \mathrm{C} / \mathrm{min}\right)$ and cooling of the sample. After each step, thermal diffusivity and XRD analyses were performed. Different samples have been tentatively studied, only a few of them withstand the heat treatments and subsequent handlings up to the highest temperatures. Only the latter are here exploited. 


\section{Results}

\section{Thermal conductivity}

The thermal conductivity as a function of burnup is reported on Figure 3. As already observed by other authors, it appears the thermal conductivity sharply decreases at the beginning of the irradiation: it is divided by approximately a factor 3 for a burnup of $12.10^{20} / \mathrm{cm}^{3}$, i.e. about $1 \%$ of total boron. Comparing the Hyperbare and Fracasse results at similar burnups $\left(\sim 25.10^{20} / \mathrm{cm}^{3}\right)$, it appears that the thermal conductivity in the Fracasse sample is about 10 percent lower. This could correspond to a lower irradiation temperature (Table 2: the inversed axial temperature evolution at the periphery of the pellets at the end of the irradiation arises from the conjunction of the lowering of the volume power by ${ }^{10} \mathrm{~B}$ depletion, the reduction of the pellet - clad gap by swelling and compaction and the partial filling of the cracks by sodium): in this temperature range, an irradiation temperature difference about $50-100^{\circ} \mathrm{C}$ then leads to a significant thermal conductivity difference.

As mentioned above, annealings have been performed only on the less consumed samples. The results are reported hereunder (Figure 4 to Figure 7) for 2 Hyperbare samples (heights 730 and $480 \mathrm{~mm}$, respectively burnup $12.10^{20} / \mathrm{cm}^{3}$ and $29.10^{20} / \mathrm{cm}^{3}$ ) and one Fracasse sample.

\section{Structure and microstructure}

Selected areas of the X-ray diffraction diagrams of a non-irradiated reference material and a highly irradiated sample (burnup $=82.10^{20} / \mathrm{cm}^{3}$ ) are reported on Figure 8 . It first appears that the irradiated material is still well crystallized (the baseline shows low and wide bumps in the small angles range meaning some kind of disorder). The diagram of the irradiated sample shows widely broadened lines. This broadening partially hides the absorption dissymmetry effect. The lines positions are not significantly shifted this meaning low unit cell parameters variation.

The Rietveld refinements have been performed in two steps. First, refining the diffraction diagram of the reference, non-irradiated sample allows determining its structure parameters (cell parameters, atomic positions, site occupations) but more importantly the experimental parameters (apparent X-ray beam linewidth, absorption-induced asymmetry). The latter have then been re-used for refining the diagrams obtained with the irradiated samples. For the analyses of the diagrams of the annealed samples, the first analysis has been performed on the last diagram, assuming a $2200^{\circ} \mathrm{C}$ heat treatment allows full annealing the structure, then going back to the lower annealing temperatures: this allows having a better reference.

The cell parameters of the samples of the Hyperbare- 1 experiment as a function of burnup are reported on Figure 9. No clear evolution can be seen. This results from high correlations during the Rietveld refinement 
between the cell parameters, the decentering of the sample and the asymmetry of the lines: such effects could not be identified on a classical line-to-line analysis. Regarding the last effect, the asymmetry of the lines depends on the (hkl) diffraction indexes, leading for some lines to an inverse asymmetry and requiring introducing extra terms to the experiment ones. It then flows that the line width, then the line broadening, depends on the (hkl) indexes. More precisely, it appears that the more the diffracting planes are close to the basal plane of the hexagonal structure, the more the lines are broadened. We had already identified this effect in our previous studies [7]. To take this effect into account, we introduced extra terms to the linewidths directly correlated to the (0OI) direction. In the XND software, this is straightforward since the dependency of the linewidth on the crystallographic directions is explicitly described with Legendre polynomials. The results we then obtain are reported on Figure 10. Here, systematic evolutions can be seen. First, the components along the (00l) direction are much higher than along the basal plane, both for the coherent diffracting domains size and the microstrains. Second, a clear evolution appears as a function of burnup, with a sharp increase up to about $4.10^{21} / \mathrm{cm}^{3}$ then a slow increase up to the highest burnup.

The analyses of the diagrams obtained after the annealing sequences for the $12.10^{20} / \mathrm{cm}^{3}$ burnup sample of the Hyperbare experiment and for the Fracasse experiment are reported on Figure 11. Complex evolutions are evidenced they will be tentatively discussed hereunder.

\section{Discussion}

The results we present here aim at a better description of the behavior of boron carbide when irradiated in a FNR. This is required first to estimate the actual working conditions of the material and the absorber component. This is also necessary for safety evaluations, e.g. to evaluate the margins in case of incident. In this frame, the thermal conductivity is of primary importance, but the structural parameters evolution could help understanding the damage processes of the material, and then the limits of the damage.

\section{Thermal conductivity}

\section{Influence of burnup}

The evolution of the thermal conductivity as a function of burnup we observe (Figure 3 ) is coherent with the results available in literature. Comparing with the most recent and comprehensive results [4], we observe similar evolutions, with a sharp decrease at the very beginning of the irradiation, and a modification of the shape of the $k(T)$ curves from hyperbolic to nearly flat. However, we obtain a somewhat lower damage of 
the thermal conductivity: the $\mathrm{k}(\mathrm{T})$ curve we obtain at a $82.10^{20} / \mathrm{cm}^{3}$ burnup is similar to the one at $47.10^{20} / \mathrm{cm}^{3}$ as obtained by Maruyama et al. This could be attributed to different irradiation conditions, e.g. neutron fluence then actual irradiation temperature: this can be seen on Figure 3. The Fracasse sample has been irradiated at a lower temperature than the corresponding Hyperbare ones at the same fluence and the thermal conductivity appears somewhat lower. This could also be attributed to the material characteristics, e.g. magnesothermic versus carbothermic. This effect was observed on the same Fracasse experiment [6], where carbothermal samples showed a significantly lower thermal conductivity than the magnesothermal one. The differences between the sets of data can be as high as about 20 percent, the consequence being thermal gradient modifications in the same order.

Figure 3 and Figure 12 both show a modification of the shape of the $k(T)$ curves. As burnup increases, the shape of the $k(T)$ curve changes from the hyperbolic-like one corresponding to a semiconducting or insulator material to a nearly flat one corresponding to a high disorder. This means a high density of diffusion centers in the materials and the disappearance of the long wavelength phonons. This could be identified to the high density of helium bubbles, leading to a characteristic distance between the bubbles about a few tens of nanometers [18].

\section{Annealing}

When looking at Figure 6-right, a sharp slope discontinuity appears on the evolution of the thickness of the sample (after soft polishing to remove possible oxidation) at about $1600^{\circ} \mathrm{C}$. This temperature corresponds to the admitted brittle to ductile temperature threshold (BDTT) of boron carbide [19]. Here, crossing this transition could allow a relaxation of the helium pressure in the bubbles, this leading to a significant swelling of the sample: such a consideration should be taken into account when looking at safety issues. However, the resulting swelling is much lower than could be achieved if the pressure was fully relaxed. On the other hand, the thermal conductivity after the last annealing at $2200^{\circ} \mathrm{C}$ is by about $25 \%$ lower than the nonirradiated one. This difference could then be explained by considering the bubbles volume behaves like porosity on the thermal conductivity: classical laws lead to a variation of the thermal conductivity about twice faster than porosity variation. But it is also worth considering the actual microstructure of the material. Studies in progress [20] have shown that annealing at $1500^{\circ} \mathrm{C}$ a helium implanted boron carbide sample leads to coalescence of the helium bubbles located into the grain boundaries, then a possible full opening of the latter: the resulting thermal barriers will certainly have strong effect on thermal conductivity despite a small volume change. This also means that the helium bubbles remain in the material up to the highest temperatures here attained: analyzing helium retention rate requires melting the material.

Looking at Figure 4 to Figure 7, it appears most of healing of the thermal conductivity arises from about $1000^{\circ} \mathrm{C}$ up to $1500^{\circ} \mathrm{C}$. This certainly is important on a safety point of view: the restauration of the thermal 
conductivity induces that the temperature increase of the control elements, in case of loss of coolant, will be limited. In both cases (Hyperbare and Fracasse), this temperature range is higher than the estimated irradiation temperatures. This means the defects originating in the conductivity decrease cannot be healed just above the irradiation temperature: this parameter (thermal conductivity annealing) could then not be used to evaluate the irradiation temperature, as can be done for example in the case of silicon carbide [21, 22]. The influence of structural damage is tentatively discussed hereunder.

In the case of the low burnup sample (Hyperbare, $12.10^{20} / \mathrm{cm}^{3}$ ), a full healing of the thermal conductivity is obtained after annealing at high temperature. For the higher burnups (Hyperbare, $29.10^{20} / \mathrm{cm}^{3}$ and Fracasse, $25.10^{20} / \mathrm{cm}^{3}$ ), healing is at best about $75 \%$, with a low dependence on the irradiation temperature. As discussed here above, this residual damage can be attributed to the helium bubbles, either in the grain boundaries or intragranular. The difference between $12.10^{20} / \mathrm{cm}^{3}$ and about $25.10^{20} / \mathrm{cm}^{3}$ could then be related to the helium retention rate. Hollenberg [23] has shown a high helium release rate up to burnups about $10^{21} / \mathrm{cm}^{3}$ then a nearly full retention up to about $4.10^{21} / \mathrm{cm}^{3}$. The first value is interpreted as the nucleation threshold of helium bubbles, the second one as the setup of intragranular cracking. Then, resulting from both higher helium production and higher retention rate, a higher density of helium bubbles is expected as burnup increases, then a lower thermal conductivity after high temperature annealing.

The $k(T)$ thermal conductivity curves after irradiation at burnups above $10^{21} / \mathrm{cm}^{3}$ appear nearly flat (Figure 3). The $k(T)$ evolution of the material has then moved from a classical semiconductor, hyperbolic-like, curve to a typical disordered material shape. Disorder can here arise from irradiation defects or from a high density of phonon diffusion centers. Regarding the structural irradiation defects, we have shown $[24,25]$ that they were not stable for irradiation temperatures above $500^{\circ} \mathrm{C}$. Then, only diffusion centers can be considered. Here again, it can be assumed they are the helium bubbles and the high induced strain X-ray analyses evidence. Then, annealing the material leads to relaxation of the micro-strains (Figure 11). This explain why the restauration of hyperbolic $k(T)$ curves (Figure 4 and Figure 5 clearly show the modification of the curvature of the $k(T)$ curves) arise in the same temperature range the micro-strains anneal (1100 $\left.1500^{\circ} \mathrm{C}\right)$.

\section{Evolution of the structure}

\section{Influence of burnup}

As mentioned above, it was not possible to derive an accurate evolution of the cell parameters as a function of burnup. Only the highest burnup data show a significant decrease of the ' $c$ ' parameter: this however is coherent with the results we previously published [8], showing a contraction of the rhombohedra along its 
main diagonal. The microstructural parameters (microstrains and coherent diffraction terms of the linewidths) show a complex evolution (Figure 10):

- First, the anisotropy of the microstructural parameters (microstrains and coherent diffracting domains size) we had previously identified [7] can be correlated to the well-known distribution of the helium bubbles in the material. The bubbles are flattened discs [26], all parallel, with high internal gas pressure [27], located in the base-plane of the hexagonal structure, this generating high and anisotropic stresses. The micro-strains associated to those stresses could induce such high atomic network deformation that they destroy the coherent diffraction between the domains delimited by the bubbles; this leading to coherent diffracting domains (CDD) which shape and volume would then be directly correlated to the distribution of the bubbles.

- The structural parameters values however show a large dispersion as a function of burnup. This flow first from the low sensitivity of the Rietveld method (strong correlations between the structural parameters) on diagrams with a poor resolution and complex anisotropic line profiles. But this also could arise from the selection of the samples. First, in a given pellet, there is a large radial thermal gradient, possibly leading to significantly different structural parameters then line broadening. Second, there is a systematic temperature gradient at the center of the pellets along the absorber rod axis, the lower the position the higher the temperature, to which fluctuations superpose due to possible modifications of the sodium inner flow or the formation of helium bubbles in the $\mathrm{B}_{4} \mathrm{C}$ cracks.

The structural parameters show a sharp increase up to a burnup about $4.10^{21} / \mathrm{cm}^{3}$, especially along the ' $c$ ' axis. However, an incubation burnup about $10^{21} / \mathrm{cm}^{3}$ cannot be excluded: this would correspond to the burnup required for the nucleation of the intragranular helium bubbles. The parameters then smoothly increase. This $4.10^{21} / \mathrm{cm}^{3}$ threshold could correspond to the onset of the intragranular microcracking induced by the propagation and coalescence of microcracks originating from the helium bubbles [18, 26].

\section{Annealing}

Annealing the materials lead to quite different restauration curves for the cell parameters and the structural parameters. These show different sharp stages. In all cases, it appears most of the damage anneal below $1500{ }^{\circ} \mathrm{C}$. As mentioned above, this temperature range is lower than the BDTT transition. But different mechanisms have to be identified in order to account for the different stages we observe: cell parameters restauration, micro-strain relaxation, growth of coherent diffracting domains.

In both samples, the cell parameters annealing show a sharp stage at about $1000-1200{ }^{\circ} \mathrm{C}$. This temperature range is neither the irradiation temperature, estimated lower, nor the BDTT of the material, about $1600^{\circ} \mathrm{C}$ (cf. Figure 6, clearly showing the discrepancy between the thermal conductivity healing and the onset of the BDTT transition). This stage could however be related to lithium diffusion leading to unit cell 
reorganization [28]: in this temperature range, X-ray diffraction performed on a non-polished sample has shown extra-lines that could be attributed to lithium borates. But recent results [20] show that this temperature corresponds to a change in the intragranular helium bubbles from flat to more tridimensional. More striking are the evolutions of the cell parameter during annealing. Some authors have observed such evolution [29, 30]. In all cases (including our observations), similar evolutions are observed: an 'a' decrease together with a ' $c$ ' increase at nearly constant cell volume at the beginning of heat treatments (500 $1000^{\circ} \mathrm{C}$ ), a sharp peak in the $1000-1200^{\circ} \mathrm{C}$ range, then reverse variations followed by a quasi-plateau up to the highest annealing temperatures. But the initial values of the cell parameters and the amplitude of the evolution are very different. Different parameters can be considered to explain such differences: irradiation temperature, burnup, leading to different cell configurations, they cannot here be discussed.

Regarding the microstructural parameters, micro-strains and coherent diffracting domains (CDD), Figure 11 shows they all anneal in the $1000-1500{ }^{\circ} \mathrm{C}$ range. It is however difficult to analyze those results for those parameters have a poor sensitivity and are generally correlated in the Rietveld refinement. Only tendencies can then be drawn. Here again, we assume the micro-strains and the CDD dimensions are correlated to the distribution of the helium bubbles and internal helium pressure. As a consequence, as the micro-strains relax, coherent diffraction can again occur (even if helium bubbles are still present: such porosity only lowers the diffracted intensity). The micro-strain relaxation and the CDD growth should then be correlated. Now, the mechanisms leading to strain relaxation are still not identified. They could be associated to cell reorganization or the onset of helium diffusion: as noticed above, this temperature range corresponds to a modification of the shape of the helium bubbles, from very flat to more tridimensional. This would also require atomic or vacancies diffusion at the surface of the bubbles.

\section{Conclusion}

We have performed thermal diffusivity and X-ray diffraction analyses of boron carbide samples irradiated in the French Phenix LMFBR. Samples with a burnup up to $84.10^{20} / \mathrm{cm}^{3}$ have been analyzed. Moreover, isochronal annealing has been performed on some samples up to $2200^{\circ} \mathrm{C}$. The thermal conductivity shows a quick damage as a function of burnup, this is in good agreement with other studies. The damage heals when heating to about $1500^{\circ} \mathrm{C}$, a residual damage remains that we attribute to the retained helium bubbles. Healing is mainly attributed to the relaxation of the stresses due to helium pressure in the bubbles. This has two consequences in case of accident such as loss of coolant inducing high temperature increase: first, the 
thermal conductivity enhances, this leading to a limitation of the temperature increase in the material, but second, the material swells, this leading to potential mechanical issues with the shroud.

Further examinations should be performed in order to validate the hypothesis here performed, such as Raman spectroscopy, Transmission Electron Microscopy observations, helium diffusion and release, both on as-irradiated and on annealed materials. Minor elements but with high waste management consequences, such as tritium, should also be considered. Such a program would find a large benefit in examining the available control rods coming from the French Phenix reactor dismantling frame.

\section{Acknowledgements}

\section{References}

[1] D.E. Mahagin, J.L. Bates, D.E. Baker, "Boron carbide thermal conductivity”, HEDL-TME 73-78 (1973)

[2] J.E. Brocklehurst, B.T. Kelly, K.E. Gilchrist, D. Mottorshead, D.E.Y. Walker, S.D. Preston, "The performance of boron carbide control rod pins in the Prototype Fast Reactor", Nucl. En. 23-3 (1984) 179

[3] K.E. Gilchrist, "The thermal conductivity of boron carbide after fast neutron irradiation", High Temp. High Press. 17, 671-681 (1985)

[4] T. Maruyama, S. Onose, T. Kaito, H. Horiuchi, "Effect of Fast Neutron Irradiation on the Properties of Boron Carbide Pellets", J. Nucl. Sci. Tech. 34-10, 1006-1014 (1997)

[5] V.P. Tarasikov, R.M. Voznesenski, V.A. Rudenko, "The experience of post irradiation investigations of the BN-600 control rods in Abosrber materials, control rods and designs of shutdown systems for advanced liquid metal fast reactors", Proc. Tech. Committee Meeting Obninsk , IAEA-TECDOC-884 (1995) 153

[6] K. Froment, D. Gosset, M. Guéry, B. Kryger and C. Verdeau, "Neutron irradiation effects in boron carbides: Evolution of microstructure and thermal properties", J. Nucl. Mater. 188 (1992) 185-188

[7] D. Gosset, D. Siméone et D. Quirion, «Endommagement du carbure de bore sous irradiation neutronique: évaluation en diffraction X », J. Phys. IV France PR10 55-63 (2000)

[8] D. Simeone, D. Gosset, D. Quirion, X. Deschanels, "Study of $\mathrm{B}_{4} \mathrm{C}$ microstructure evolution under neutron irradiation by X-ray diffraction profiles analysis", J. Nucl. Mater. 264 (1999) 295 \pm 308

[9] D. Gosset, J.M. Escleine, A. Michaux, "Neutron absorber materials in fast reactors: behavior under irradiation and perspectives", Int. Conf. on Fast Reactors and Related Fuel Cycles: Safe Technologies and Sustainable Scenarios (FR13), IAEA meeting, Paris (France), 2013

[10] F. Thévenot, "Boron Carbide, A Comprehensive Review”, J. Eur. Cer. Soc. 6, 205-225 (1990)

[11] N. Vast, J. Sjakste, E. Betranhandy, "Boron carbide from first principles", $16^{\text {th }}$ Int. Conf. on Boron, Borides and Related Materials, J. of Phys.: conf. Series 176 (2009) 012002

[12] B. Kryger, D. Gosset, J.M. Escleine, "Performances of the Superphenix type absorber element" in "Absorber materials, control rods and designs of shutdown systems for advanced liquid metal fast reactors", Proc. Tech. Com. Obninsk, IAEA-TECDOC-884 (1995)

[13] D. Gosset, M. Colin, "Improvement of the Cowan method for thermal diffusivity determination", High Temp - High Press. 34, 265-280 (2002)

[14] J.F. Bérar, P. Garnier, in APD $2^{\text {nd }}$ Conference, NIST, Gaithersburg, USA, 1992, (Xnd is available on $\mathrm{ftp}: / /$ labs.polycnrs-gre.fr/pub/xnd (login: anonymous password: anonymous)). 
[15] D. Simeone, G. Baldinozzi, D. Gosset, S. Le Caer, J.F. Bérar, "Grazing incidence X-ray diffraction for the study of polycrystalline layers", Thin Solid Films 530 (2013) 9-13

[16] J.F. Bérar and G. Baldinozzi, “Modeling of line-shape asymmetry in powder diffraction”, J. appl. Cryst. (1993) 26, 128-129

[17] G.K. Williamson, W.H. Hall, “X-ray line broadening from filed aluminum and wolfram”, Acta Met., 1 (1953) 22-31

[18] T. Stoto, N. Housseau, L. Zuppiroli, and B. Kryger, "Swelling and microcracking of boron carbide subjected to fast neutron irradiations", J. Appl. Phys. 68, 3198 (1990)

[19] R. Belon, G. Antou, N. Pradeilles, A. Maître, D. Gosset, "Mechanical behaviour at high temperature of spark plasma sintered boron carbide ceramics", Cer Int. 43-8 (2017) 6631-6635

[20] V. Motte, D. Gosset, S. Miro, S. Doriot, S. Surblé, N. Moncoffre, "Helium behaviour in implanted boron carbide", EPJ Nuclear Sci. Technol. 1, 16 (2015)

[21] R. J. Price, “Annealing Behavior of Neutron-Irradiated Silicon Carbide Temperature Monitors", Nucl. Tech., 16-3 (1972), 536-542

[22] D.J. Senor, G.E. Youngblood, C.E. Moore, D.J. Trimble, J.J. Woods, "Effects of neutron irradiation on thermal conductivity of SiC-based composites and monolithic ceramics", KAPL-P-000154, annual meeting of the American Ceramic Society (1997)

[23] G.W. Hollenberg, J.L. Jackson, J.A. Basmajian, "In-reactor measurement of neutron absorber performance", Nucl. Tech., 49-1 (1980) 92-101

[24] G. Victor, Y. Pipon, N. Bérerd, N. Toulhoat, N. Moncoffre, N. Djourelov, S. Miro, J. Baillet, N. Pradeilles, O. Rapaud, A. Maître, D. Gosset, "Structural modifications induced by ion irradiation and temperature in boron carbide $\mathrm{B}_{4} \mathrm{C}^{\text {", }}$ Nucl. Instr. Meth. B 365 (2015) 30-34

[25] D. Gosset et al., to be published

[26] G.W. Hollenberg and W.V. Cummings, "Effect of Fast Neutron Irradiation on the Structure of Boron Carbide", J. Am. Cer. Soc., 60-11-12, 520-525 (1977)

[27] M.N. Bussac, L. Zuppiroli, "Stress-induced diffusion of point defects to lenticular bubbles: Self-consistent calculations of the sink strengths", Phil. Mag. A-60-1, 83-105 (1989)

[28] X. Deschanels, D. Simeone, J.P. Bonal, "Determination of the lithium diffusion coefficient in irradiated boron

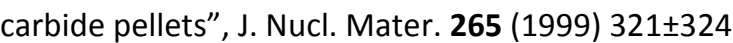

[29] G.L. Copeland, R.G. Donnelly, W.R. Martin, “Irradiation behavior of boron carbide”, Nucl. Tech., 16, 226 (1972)

[30] H. Suzuki et al., J. Nucl. Sci. Tech., "Post-irradiation annealing of boron carbide pellet irradiated in fast breeder reactor", 16[8], 588 (1979) 


\section{Table captions}

Table 1. Main characteristics of the Hyperbare-1 and Fracasse experiments (min-max burnups and volume power: from top of absorber column to reactor mid-plane)

Table 2. Estimated temperatures in the Hyperbare samples, assuming sodium partial filling of the cracks.

\section{Figure captions}

Figure 1. Cracking in an experimental Phenix control rods. Left: burnup $=1 \cdot 2 \cdot 10^{22} / \mathrm{cm}^{3}$. Right: burnup $=$ $8.5 .10^{21} / \mathrm{cm}^{3}$. Scale: outer cladding diameter $=21 \mathrm{~mm}$.

Figure $2 .{ }^{10} \mathrm{~B}$ burnup and geometric swelling along the Hyperbare-1 control rod height. $30 \mathrm{~A}, 44 \mathrm{C}$ : reference of the pins.

Figure 3. Left: thermal conductivity of the Hyperbare-1 samples as a function of burnup (from $12.10^{20}$ to $\left.82.10^{20} / \mathrm{cm}^{3}\right)$. Right: thermal conductivity of the Fracasse sample.

Figure 4. Thermal conductivity $\left(1 / T^{2}\right.$ polynomials) of the $730 \mathrm{~mm}$ height sample (B.U. $\left.12.10^{20} / \mathrm{cm}^{3}\right)$ in the Hyperbare experiment as a function of annealing temperature $\left({ }^{\circ} \mathrm{C}\right)$.

Figure 5. Annealing the thermal conductivity of the $730 \mathrm{~mm}$ height sample (B.U. $12.10^{20} / \mathrm{cm}^{3}$ ) in the Hyperbare experiment at different measurement temperatures $\left({ }^{\circ} \mathrm{C}\right)$. Left: thermal conductivity at different measurement temperatures, as compared to the initial values (full lines). Right: relative thermal conductivity.

Figure 6. Annealing the thermal conductivity of the $480 \mathrm{~mm}$ height sample (B.U. $29.10^{20} / \mathrm{cm}^{3}$ ) in the Hyperbare experiment. Left: relative thermal conductivity at different measurement temperatures $\left({ }^{\circ} \mathrm{C}\right)$. Right: thickness of the sample (solid line: linear fits with a transition at $1580^{\circ} \mathrm{C}$ ). 
Figure 7. Annealing the thermal conductivity in the Fracasse experiment (B.U. $25.10^{20} / \mathrm{cm}^{3}$ ). Left: thermal conductivity at different measurement temperatures. Right: relative thermal conductivity.

Figure 8. XRD diagrams for the non-irradiated reference material and a highly irradiated one (82.e20: burnup $82.10^{20} / \mathrm{cm}^{3}$, shifted for clarity).

Figure 9. Cell parameters variations (hexagonal frame) as a function of burnup $\left(10^{20} / \mathrm{cm}^{3}\right)$ for the Hyperbare1 samples. Error bars \pm 0.003 .

Figure 10. Material components to the XRD linewidths (full widths at half maximum) as a function of burnup. WgT: $\tan (\theta)$ component, corresponding to microstrains $(4 \varepsilon)$. WIC: $1 / \cos (\theta)$ components, corresponding to the reverse of the size of the coherent domains $(\lambda / d$, Scherrer approximation). ' 0 ': isotropic component. (0OI): component along (0OI) direction. Error bars about $\pm 20 \%$. Solid lines: eyes guides.

Figure 11. Evolution of the cell parameters (left, error bars $\sim \pm 0.0005$ ) and linewidth components (right, error bars $\sim \pm 20 \%$ ) for the $12.10^{20} / \mathrm{cm}^{3}$ Hyperbare sample (top) and $21.10^{20} / \mathrm{cm}^{3}$ Fracasse sample (bottom). Error bars have been omitted for clarity (about \pm 0.0005 for cell parameters and \pm 0.1 for linewidths). Full lines: eyes guides.

Figure 12. Thermal conductivity of $\mathrm{B}_{4} \mathrm{C}$ irradiated in Joyo as a function of burnup, from [4].

Figure 13. Annealing hexagonal cell parameters in irradiated boron carbide, from [29] and [30]. 


\section{Tables}

Table 1. Main characteristics of the Hyperbare-1 and Fracasse experiments (min-max burnups and volume power: from top of absorber column to reactor mid-plane)

\begin{tabular}{lcc}
\hline Experiment & Hyperbare-1 & Fracasse \\
\hline Absorber & Magnesothermal $\mathrm{B}_{4} \mathrm{C}$ \\
\hline Relative density & \multicolumn{2}{c}{0.96} \\
\hline${ }^{10} \mathrm{~B}$ enrichment & 0.48 \\
\hline Pellets diameter $(\mathrm{mm})$ & 23.5 & 6.6 \\
\hline Grain size $(\mu \mathrm{m})$ & $2-5$ & $2-5$ \\
\hline Irradiation duration $\left(\mathrm{efpd}^{*}\right)$ & 399 & 43 \\
\hline Min-max burnup $\left(10^{20} / \mathrm{cm}^{3}\right)$ & $12-140$ & $\sim 25$ \\
\hline Volumic power $(\mathrm{n}, \alpha)$ reactions $\left(\mathrm{W} / \mathrm{cm}^{3}\right)$ & $15-165$ & $\sim 160$ \\
\hline $\mathrm{B}_{4} \mathrm{C}$ temperature, $\min -\max \left({ }^{\circ} \mathrm{C}\right)$ & $500-1100$ & $500-600$ \\
\hline
\end{tabular}

* efpd: equivalent full power days (equivalent irradiation duration reported to a full power operation of the reactor)

Table 2. Estimated temperatures in the Hyperbare samples, assuming sodium partial filling of the cracks.

\begin{tabular}{cccccc}
\hline Height & Burnup & \multicolumn{2}{c}{ Beginning of life $\left({ }^{\circ} \mathrm{C}\right)$} & \multicolumn{2}{c}{ End of life $\left({ }^{\circ} \mathrm{C}\right)$} \\
\cline { 3 - 6 }$(\mathrm{mm})$ & $\left(10^{20} / \mathrm{cm}^{3}\right)$ & center & periphery & center & periphery \\
\hline 730 & 12 & 560 & 530 & 600 & 530 \\
\hline $\mathbf{4 8 0}$ & $\mathbf{2 9}$ & $\mathbf{5 9 0}$ & $\mathbf{5 2 5}$ & $\mathbf{6 6 0}$ & $\mathbf{5 0 0}$ \\
\hline 340 & 49 & 625 & 525 & 710 & 490 \\
\hline 190 & 67 & 700 & 540 & 800 & 480 \\
\hline 80 & 82 & 800 & 560 & 890 & 470 \\
\hline
\end{tabular}




\section{Figures}
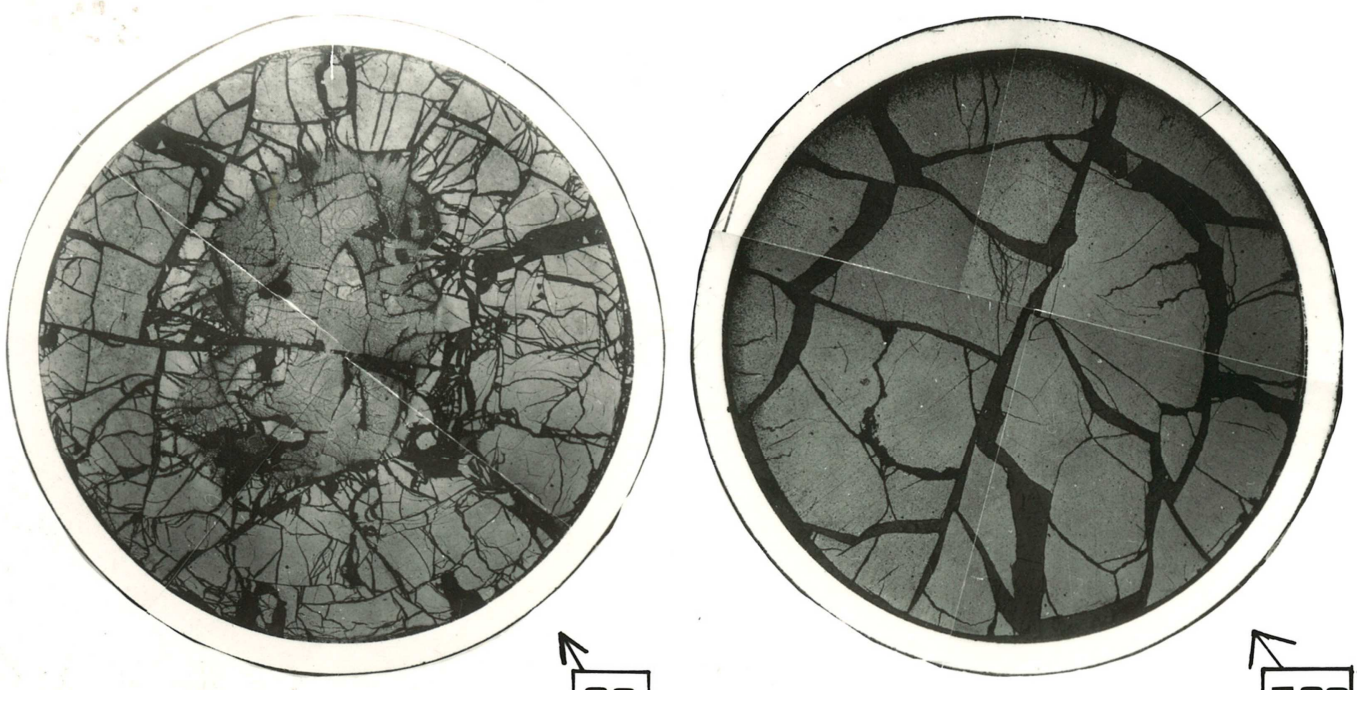

Figure 1. Cracking in an experimental Phenix control rods. Left: burnup $=1 \cdot 2 \cdot 10^{22} / \mathrm{cm}^{3}$. Right: burnup $=$ $8.5 .10^{21} / \mathrm{cm}^{3}$. Scale: outer cladding diameter $=21 \mathrm{~mm}$.
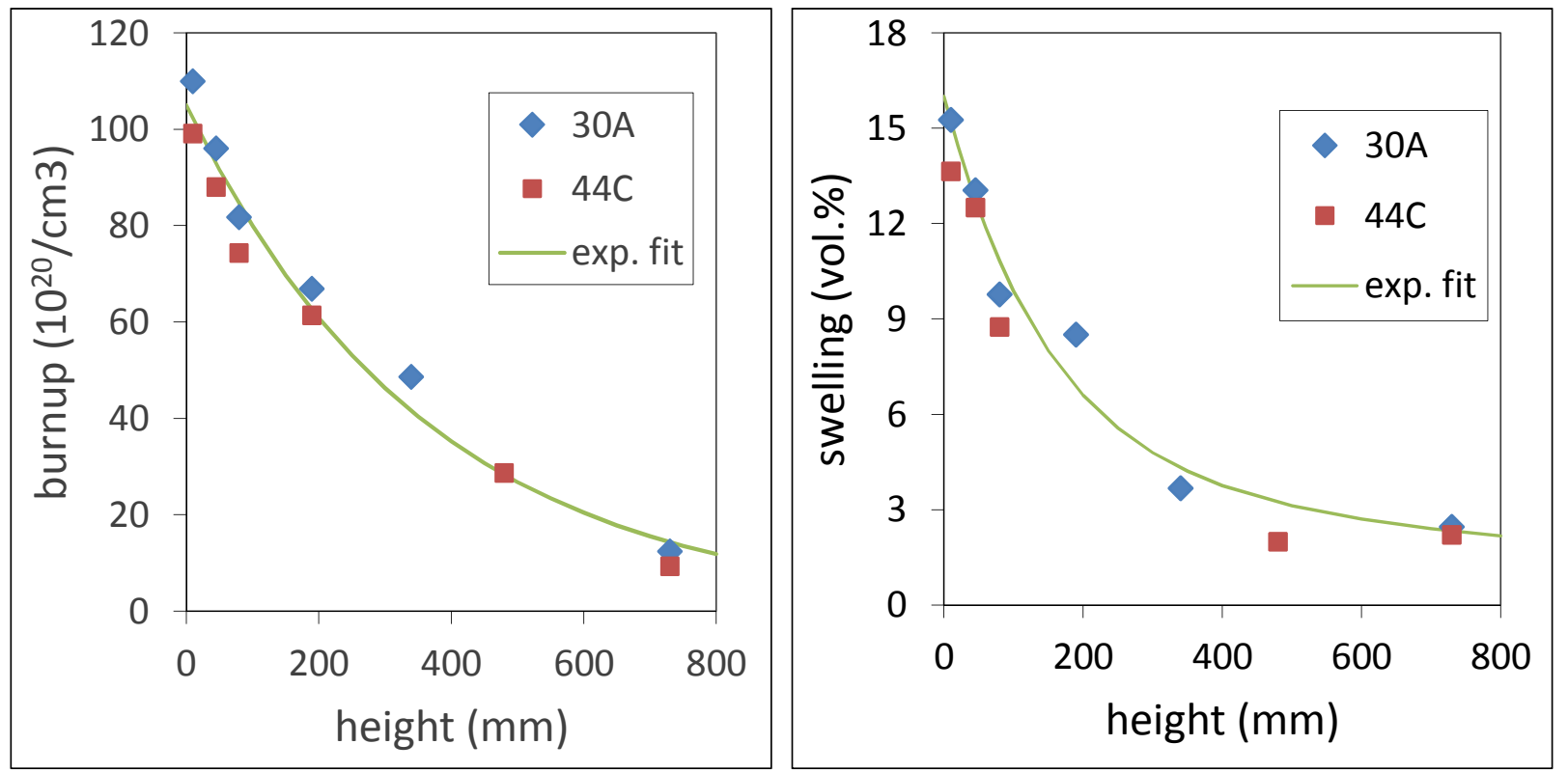

Figure $2 .{ }^{10} \mathrm{~B}$ burnup and geometric swelling along the Hyperbare-1 control rod height. 30A, 44C: reference of the pins. 

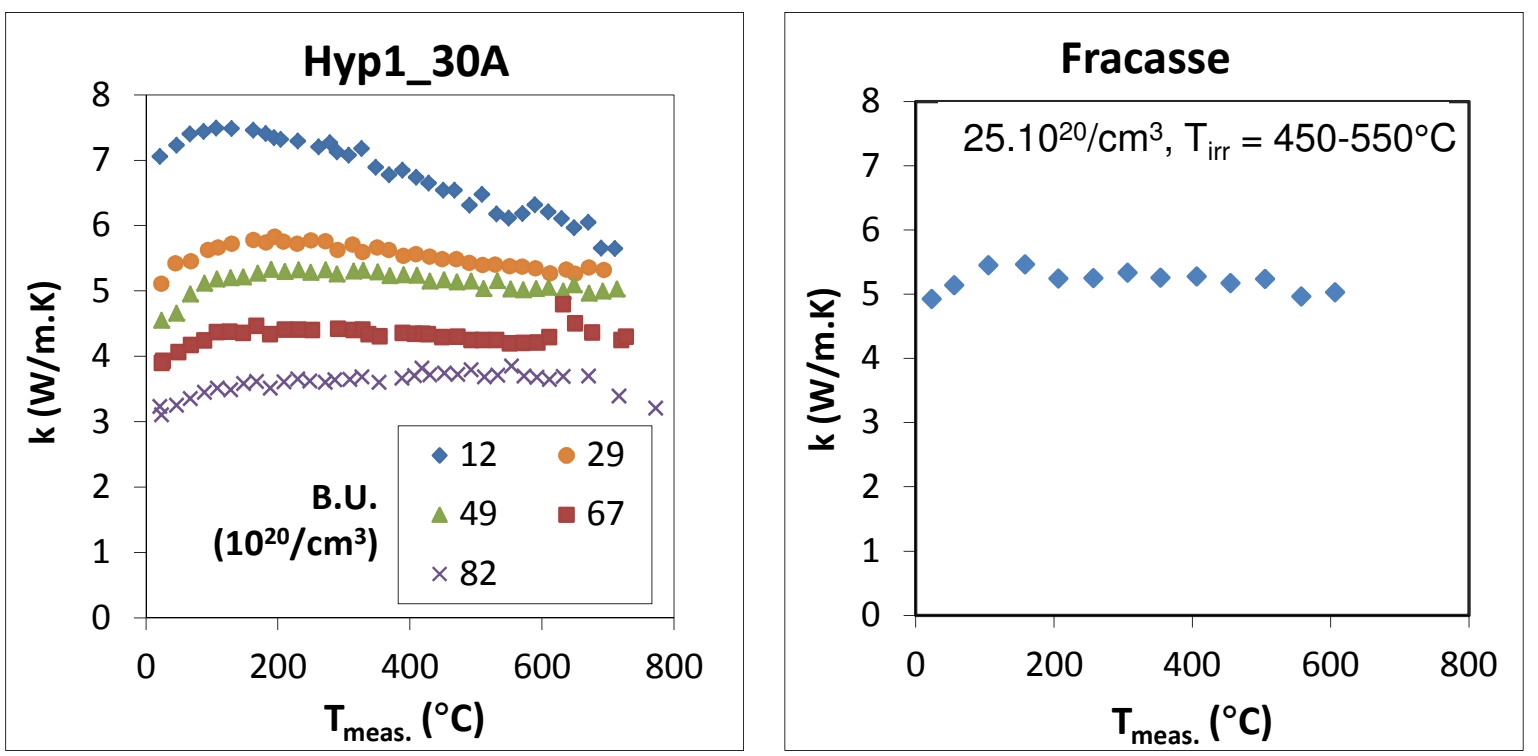

Figure 3. Left: thermal conductivity of the Hyperbare-1 samples as a function of burnup (from $12.10^{20}$ to $82.10^{20} / \mathrm{cm}^{3}$ ). Right: thermal conductivity of the Fracasse sample.

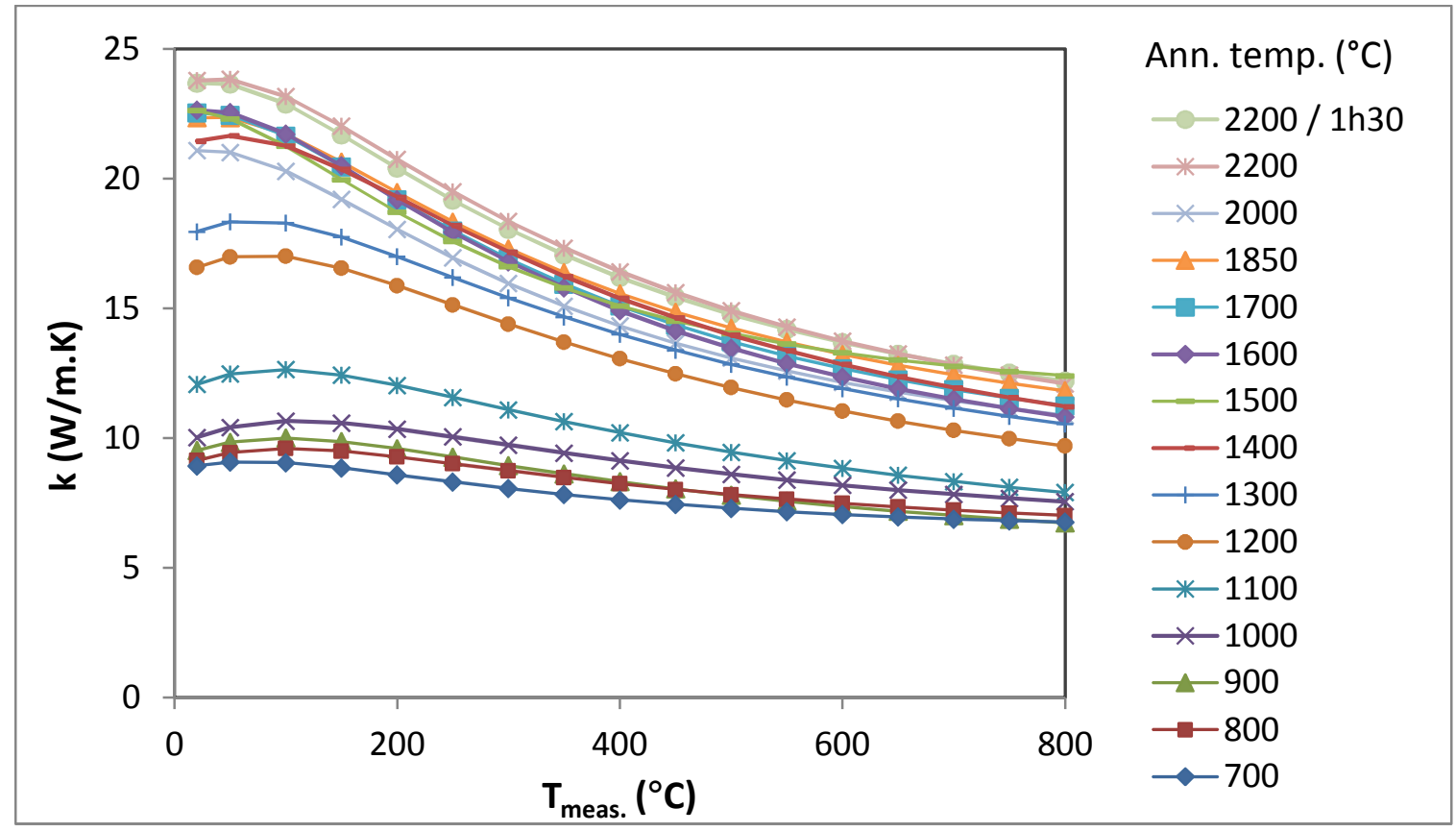

Figure 4. Thermal conductivity $\left(1 / \mathrm{T}^{2}\right.$ polynomials) of the $730 \mathrm{~mm}$ height sample $\left(B . U .12 .10^{20} / \mathrm{cm}^{3}\right)$ in the Hyperbare experiment as a function of annealing temperature $\left({ }^{\circ} \mathrm{C}\right)$. 


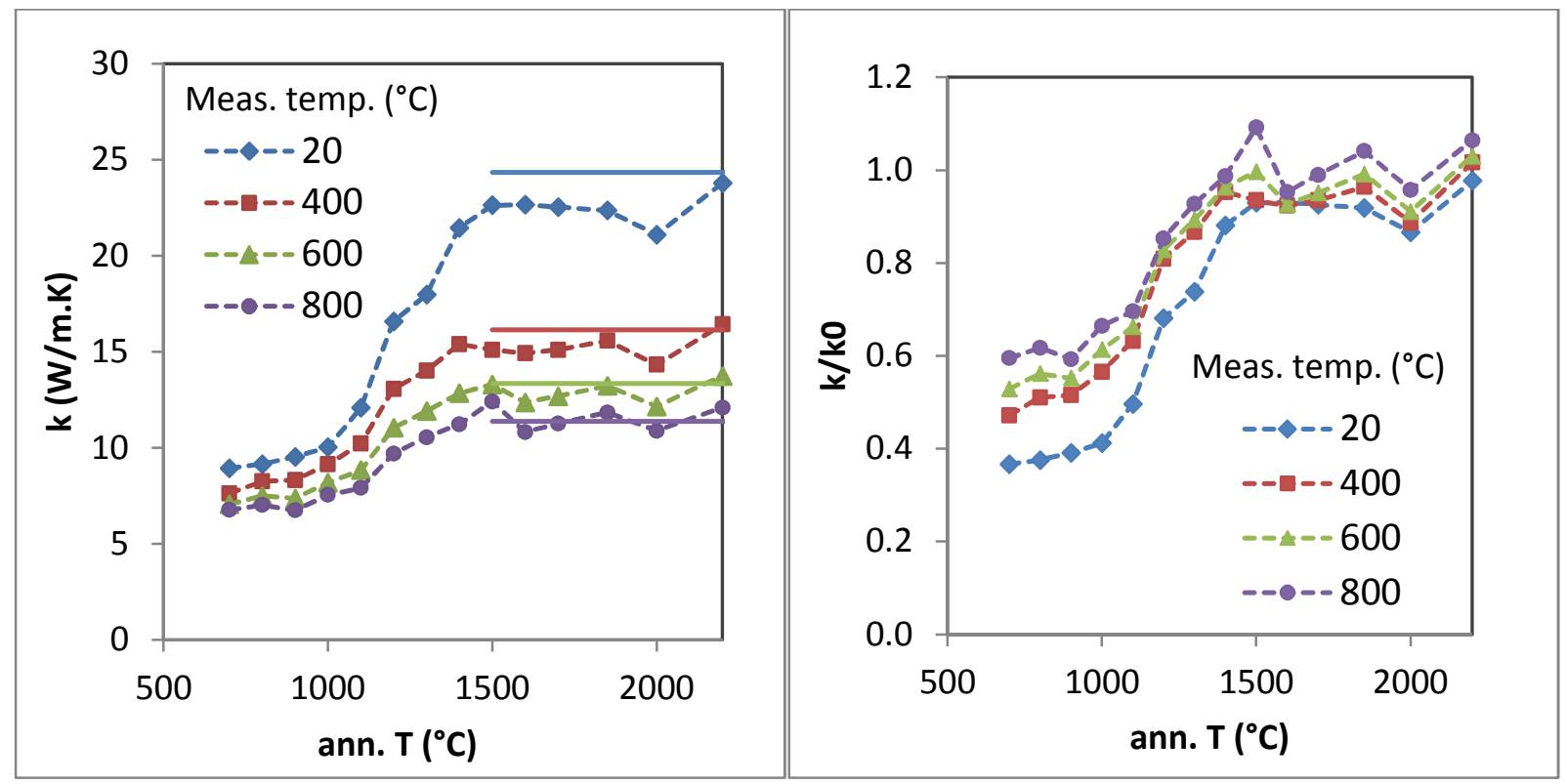

Figure 5. Annealing the thermal conductivity of the $730 \mathrm{~mm}$ height sample (B.U. $12.10^{20} / \mathrm{cm}^{3}$ ) in the Hyperbare experiment at different measurement temperatures $\left({ }^{\circ} \mathrm{C}\right)$. Left: thermal conductivity at different measurement temperatures, as compared to the initial values (full lines). Right: relative thermal conductivity.
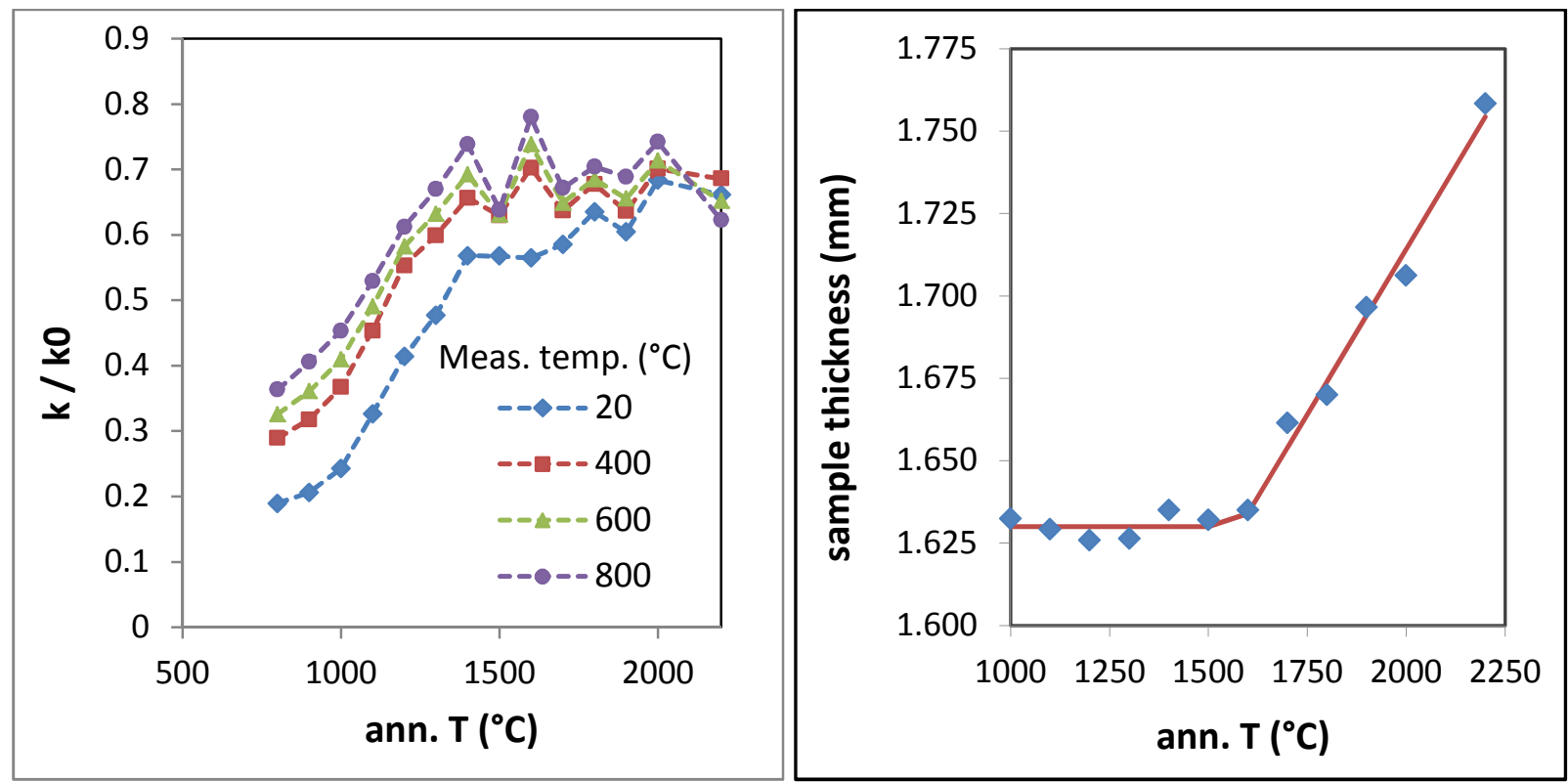

Figure 6. Annealing the thermal conductivity of the $480 \mathrm{~mm}$ height sample (B.U. $29.10^{20} / \mathrm{cm}^{3}$ ) in the Hyperbare experiment. Left: relative thermal conductivity at different measurement temperatures $\left({ }^{\circ} \mathrm{C}\right)$. Right: thickness of the sample (solid line: linear fits with a transition at $1580^{\circ} \mathrm{C}$ ). 


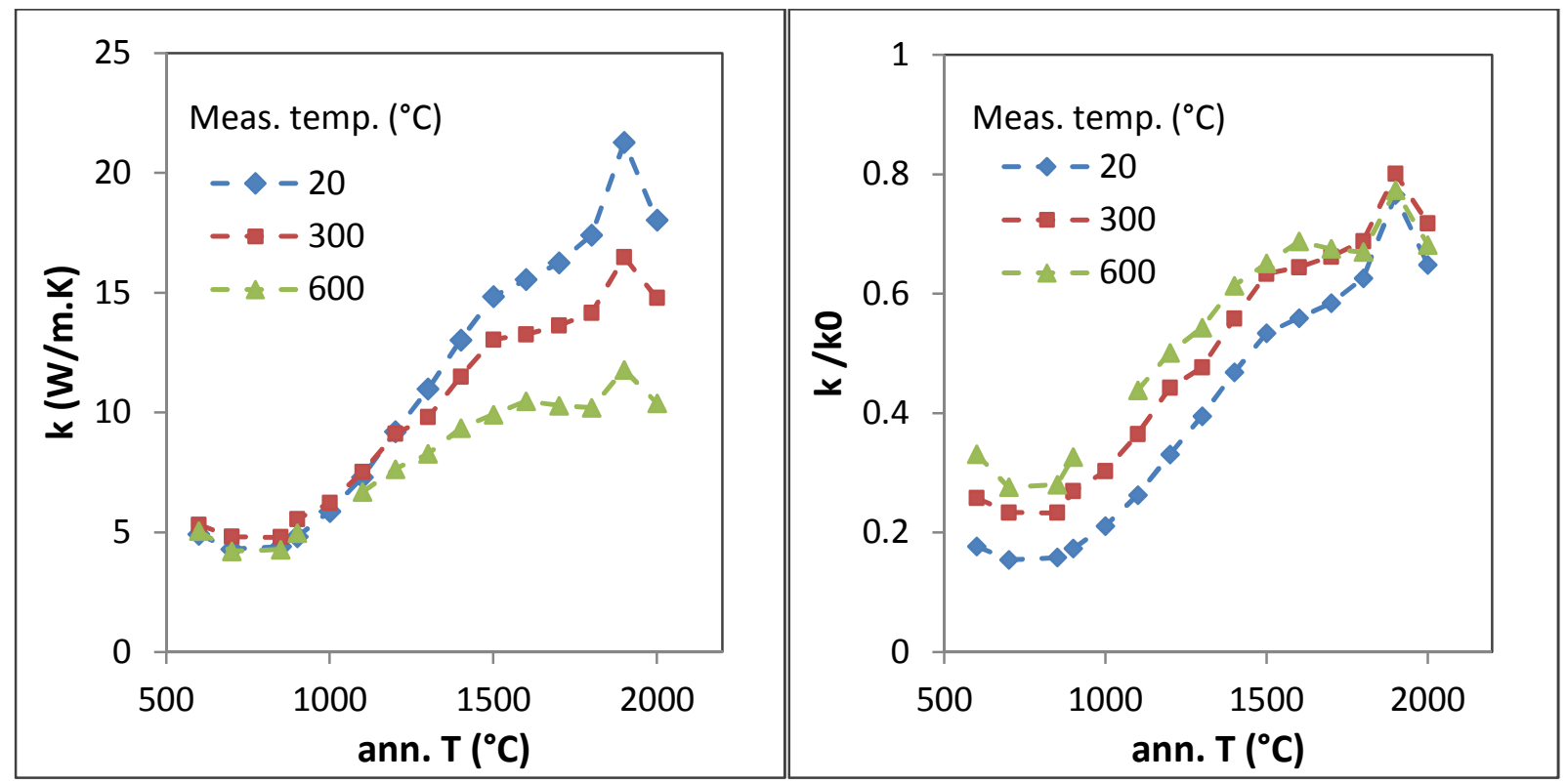

Figure 7. Annealing the thermal conductivity in the Fracasse experiment (B.U. $25.10^{20} / \mathrm{cm}^{3}$ ). Left: thermal conductivity at different measurement temperatures. Right: relative thermal conductivity.

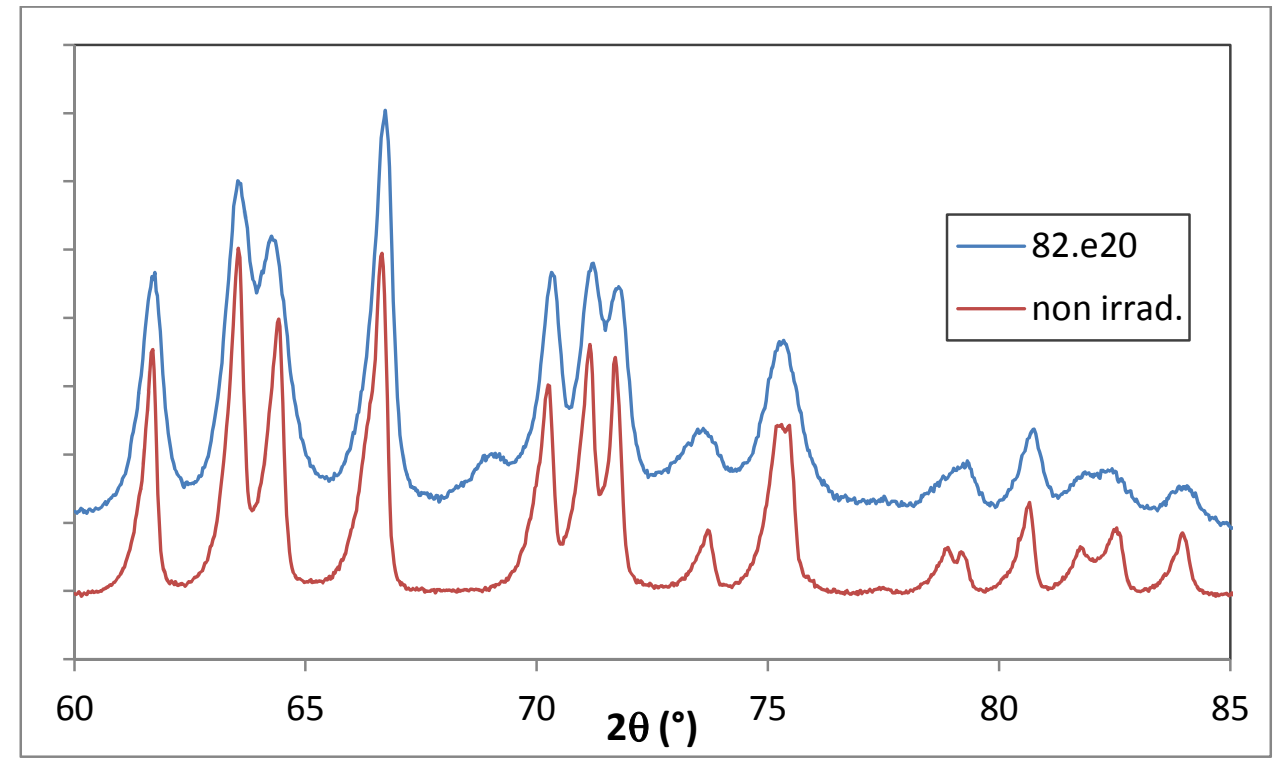

Figure 8. XRD diagrams for the non-irradiated reference material and a highly irradiated one (82.e20: burnup $82.10^{20} / \mathrm{cm}^{3}$, shifted for clarity). 


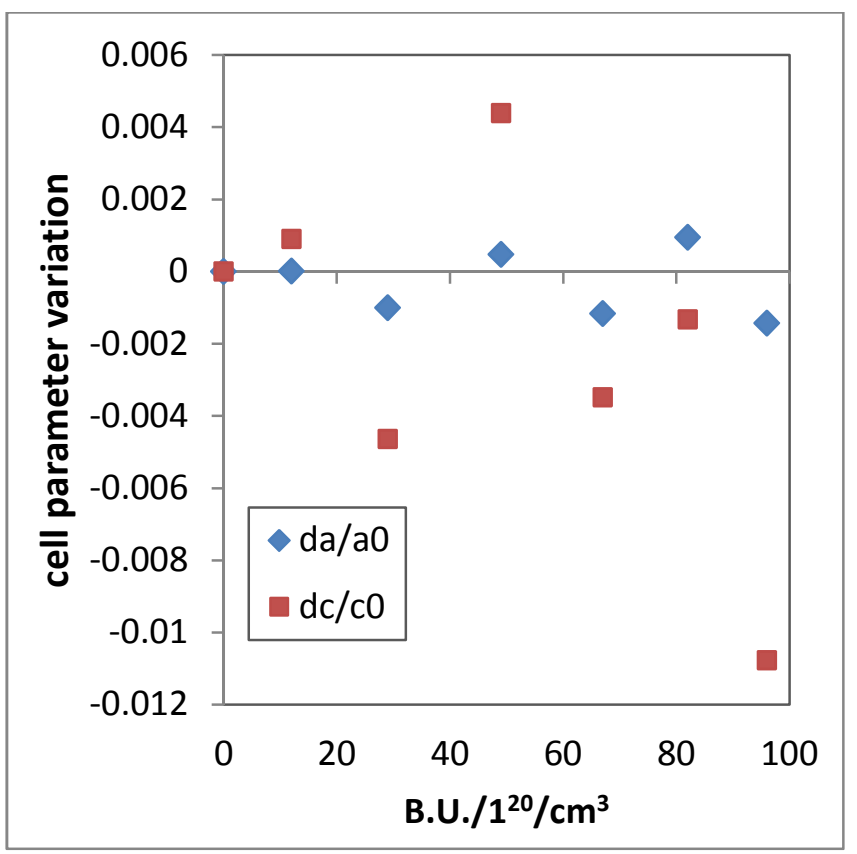

Figure 9. Cell parameters variations (hexagonal frame) as a function of burnup $\left(10^{20} / \mathrm{cm}^{3}\right)$ for the Hyperbare-1 samples. Error bars \pm 0.003 .

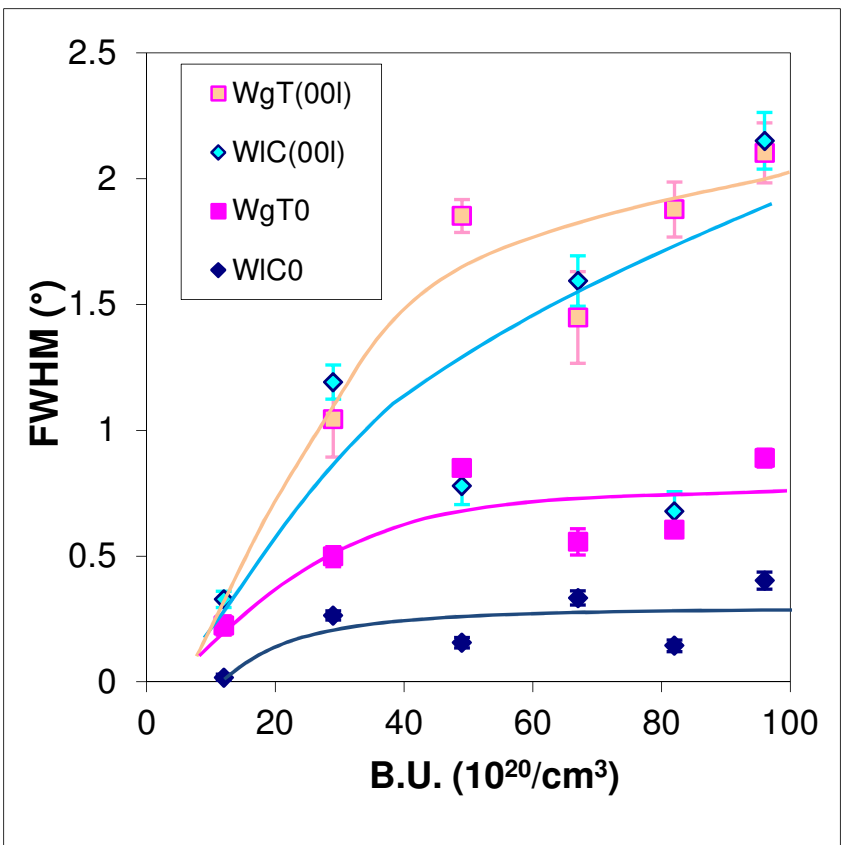

Figure 10. Material components to the XRD linewidths (full widths at half maximum) as a function of burnup. WgT: $\tan (\theta)$ component, corresponding to microstrains $(4 \varepsilon)$. WIC: $1 / \cos (\theta)$ components, corresponding to the reverse of the size of the coherent domains $(\lambda / d$, Scherrer approximation). ' 0 ': isotropic component. (00l): component along (00l) direction. Error bars about $\pm 20 \%$. Solid lines: eyes guides. 

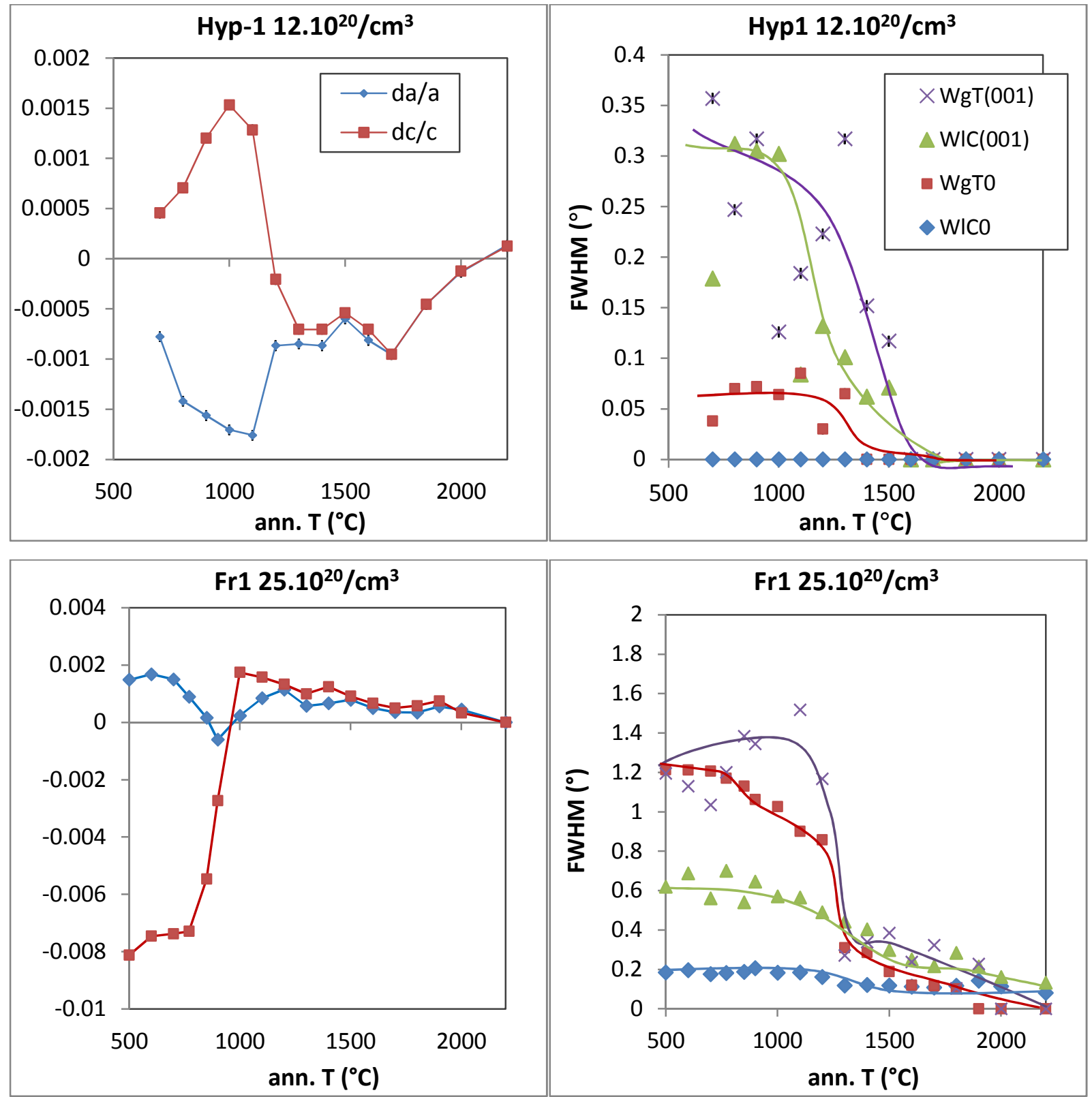

Figure 11. Evolution of the cell parameters (left, error bars $\sim \pm 0.0005$ ) and linewidth components (right, error bars $\sim \pm 20 \%$ ) for the $12.10^{20} / \mathrm{cm}^{3}$ Hyperbare sample (top) and $21.10^{20} / \mathrm{cm}^{3}$ Fracasse sample (bottom). Error bars have been omitted for clarity (about \pm 0.0005 for cell parameters and \pm 0.1 for linewidths). Full lines: eyes guides. 


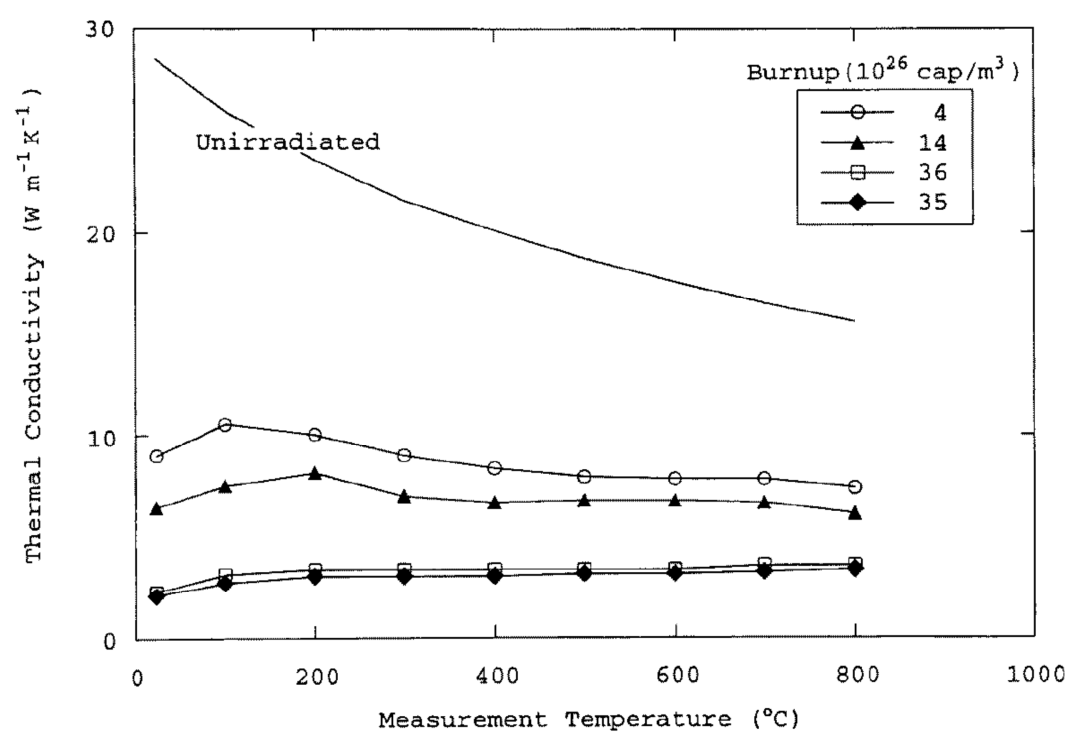

Figure 12. Thermal conductivity of $\mathrm{B}_{4} \mathrm{C}$ irradiated in Joyo as a function of burnup, from [4].
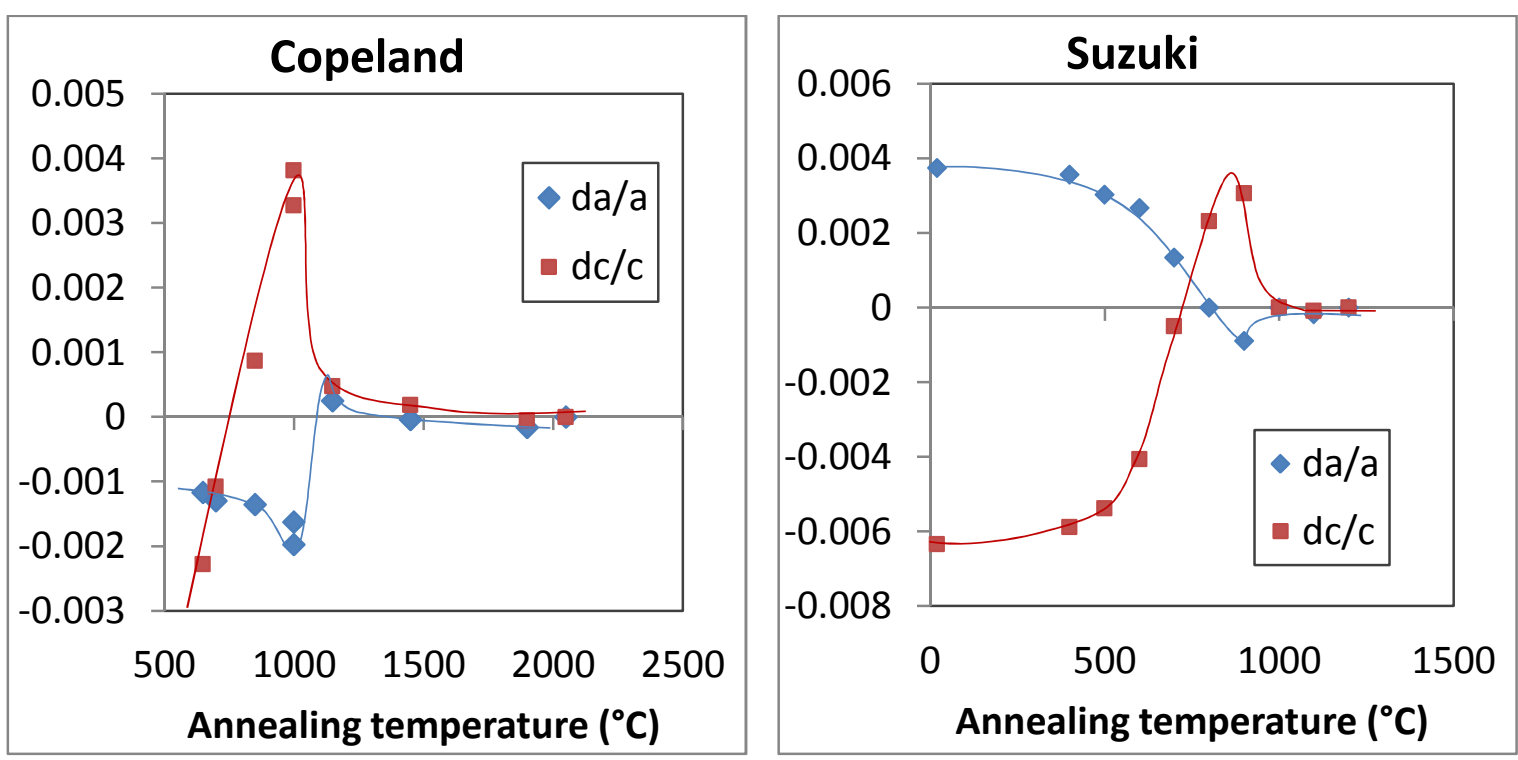

Figure 13. Annealing hexagonal cell parameters in irradiated boron carbide, from [29] and [30]. 